\title{
Medicated Adhesive Patch Dosage Form
}

National Cancer Institute

\section{Source}

National Cancer Institute. Medicated Adhesive Patch Dosage Form. NCI Thesaurus.

Code C68988.

A solid composed of an impermeable occlusive backing, a formulation matrix in which the active and/or inert ingredient(s) are dissolved or dispersed and an adhesive layer. It is intended for external application. 